\title{
Breaking the Code - How to get your ET Faculty Tenure
}

\author{
Jerry W. Samples \\ University of Pittsburgh at Johnstown
}

\begin{abstract}
Just like hiring practices, there are variations in the tenure and promotion practices at every college and university. The leaders in Engineering Technology programs must understand the "practices" that apply to tenure and promotion, and be able to guide their faculty such that they are competitive when it is time for tenure and promotion. The "practices" and the rules that guide them are often obscure, leaving many tenure stream faculty members to guess what is required and how to navigate the process. Breaking the code (the rules for tenure and promotion and how they apply to ET faculty who consult) is the job of the leader. This paper will address the subject of being ready for the tenure when the time comes, and the steps necessary to prepare ET faculty for scrutiny by their peers.
\end{abstract}

The Problem

There is a code within the walls of the university and it must be broken to achieve tenure and promotion. New faculty, especially those from industry, need to break the code but they need help. In previous papers there have been discussions of mentoring and working with faculty, ${ }^{1-3}$ but there was never an attempt to define what makes a new professor attractive to the rest of the university when it comes time for renewal and tenure. How good must teaching be? How do we convey the professional development and scholarship achievements associated with consulting to the promotion and tenure committee? How do we compare ET faculty (Ph.D. or M.S.) who are not performing research based activities with a professor in social science or humanities who is research oriented? What other things can be accomplished to make the ET faculty member look like other faculty on campus?

Rose $^{4}$ states that: "Promotion and tenure of engineering technology (ET) faculty requires evaluation of an individual's proficiency in teaching, scholarship and service. The importance of each of these may vary from one institution to another. For a new ET faculty member, understanding what is expected at their institution in these areas is important for putting together a strong plan leading to promotion and tenure." Faculty interviews conducted in 1998, ${ }^{1}$ resulted in two responses that further emphasize the need for help in defining expectations: "Keep me on the tenure track." and "Guidance in finding the right stops along the tenure time-line, i.e., good committees, assistance with initial papers and other activities." Sanders ${ }^{5}$ has noted that many talented young professionals have decided not to pursue careers in higher education because of the increasing expectations for tenure and promotion. Akinkuoye and Odesina ${ }^{6}$ state: "The supervisor is in a position to observe and assist the junior faculty member to maintain the level of motivation needed to succeed in the job. Mutual commitments between the employer and the faculty member need to be maintained by the supervisor to prevent demotivation of the faculty 
member." Buchanan, ${ }^{7}$ relates the comments of a colleague: "The professor stated that tenure was like a bowling game in which the pins are hidden." This is, of course, an unacceptable way to treat tenure stream faculty. Buchanan further relates that, "A good faculty development plan goes a long way towards "unhiding the pins"." But, where does a good faculty development plan originate, and how is it related to the faculty?

Some of the very things that attract excellent field engineers, those attractive to ET programs, to the teaching profession set them apart from their university colleagues. Their decision making, their no-nonsense approach to meetings and their direct route to publication vice the esoteric way of academe - all separate the new ET faculty from their colleagues. ET faculty need to accept the processes of academe and need to become "comfortable" with the academy. They need to be taught to teach so that they do it well and to a standard that is above their contemporaries in other departments. They must be excellent teachers. They must be exceptional in the translation of their consulting into scholarship in order to be recognized as scholars within the university. Making sure to dot the " $i$ 's" and cross the " $t$ ' $s$ " in every interaction on campus. This "awareness" of the academy comes in the form of a faculty development plan, and it is the ET leadership that must make the plan and make it a living document.

Breaking the code

Breaking the code, or "unhiding the pins" is the responsibility of the ET leadership. In some cases the code has been well defined and is operationally smooth. In other cases, the evolution of tenure at the university and the incorporation of ET faculty qualifications and scholarly pursuits have not meshed so easily. The remainder of this paper will address a code breaking sequence that has worked in an evolving situation. The process is applicable at any university and should be constantly reviewed to ensure that there are no surprises when ET faculty members reach their promotion and tenure review.

There are four important hurdles in the development of a faculty member before their tenure review. Faculty must excel in teaching, scholarship, service, and collegiality. Collegiality is a facet of the promotion and tenure process that is seldom addressed. It has to do with the individual, AND it has to do with the attitude of the ET faculty in general. The truth of this statement will become obvious as the paper develops and the tie between the code and the expectations of the ET faculty are made to coincide.

Teaching and service are two areas that can be handled with some ease. Excellence in teaching can be taught. Faculty members should be monitored to ensure that they maintain the attitude that teaching is really their primary job. They need to know that good teaching requires preparation, an organized presentation of the material, honoring of office hours, and respect for the student body. Faculty can be visited in class, can be sent to courses where teaching is emphasized and can be mentored by local master teachers. Teaching can be evaluated against the peer group with clearly delineated standards of excellence, or at least satisfactory performance. Good teaching is essential at every university, and even those focusing on research, will not tolerate bad teachers. So, it is easy to resolve the teaching portion of the four hurdles: bad teachers should go, good ones should stay. Service is similar in that it is easy to evaluate: faculty members either provide valuable service, or they do not. Since the strength of 
service activities vary, new faculty members should be directed to service opportunities that are well regarded. Service is tied to collegiality and often provides the activities whereby faculty members from other disciplines meet the ET faculty for the first time. Collegiality is measured during these meetings, but from personal observation, collegiality between ET faculty and their colleagues has its roots in the area of scholarship. When ET faculty members insist on counting paid consulting as scholarship, they may lose the hard earned respect of their non-ET colleagues.

For some years it has been apparent that many in the ET community believe that scholarship is equivalent to professional development and that professional development is equivalent to consulting. ABET's insistence that ET faculty stay current, and have a professional development program, seems to support this contention. Recent discussions with senior ET administrators indicate that this is the way many advise their faculty. Thus, ET faculty members are told that if they consult, they have engaged in the necessary scholarship and should therefore be promoted based on consulting alone. Interestingly enough, a team from the Engineering Technology Division of ASEE is looking into this issue and plan to present, Professional development guidelines for Engineering Technology faculty, at CIEC next February. This idea of ET guidelines versus university guidelines will not work at most universities and can lead to problems in the promotion and tenure of new ET faculty, and in the overall collegiality of the faculty across campus. Simply put, the University does not care what ABET or ASEE says, the University has its own rules and practices which govern tenure and promotion, and ET faculty must abide by these rules just as other faculty within the University do. The collegiality issue slips in when ET faculty separate themselves from the rules of the University.

For some years, consulting was considered as professional development by the ET Division at the author's university. Unfortunately, the University did not consider paid consulting as a form of scholarship for promotion and tenure cases. ${ }^{3}$ This created a great deal of concern for ET faculty and vilified critics from across campus who thought that paid consulting was the antithesis of normal scholarship. Resolving this issue became a priority of the leadership across the University. The process put in place was reported at the 2004 ASEE Annual conference. ${ }^{3}$ Simply stated, the scholarships of application and teaching are combined to bring consulting into the academy. Reporting on the results of this combination at appropriate meetings and in journals provides the scholarship element recognized by the university. With this issue resolved, the code could now be broken and faculty provided with direction that should allow for successful applications for tenure and promotion.

The steps to breaking the code are:

a. Read the promotion and tenure document. This was emphasized by Lahidji ${ }^{8}$.

b. Regard teaching and service as areas that can be learned or accomplished by good faculty and recruit accordingly.

c. Determine what levels of professional development are required by the Campus Status (Promotion and Tenure) Committee.

d. Talk to colleagues about the promotion and tenure process.

e. Transform internal (ET) promotion guidelines to incorporate current standards. Just because it was done some way 25 years ago when the institution was young doesn't mean that standards have been stagnant.

Proceedings of the 2005 American Society for Engineering Education Annual Conference and Exposition Copyright (C) 2005, American Society for Engineering Education 
f. Interpret the direction of the University and find ways to make what the ET faculty do acceptable to their colleagues. Look to Boyer's model ${ }^{9}$ to help in this regard.

g. Press for interdisciplinary collaborations to get others on board with the scholarship being accomplished by the ET faculty.

h. Set annual goals that faculty must attain and then provide a written report on their success or failure. Johnson ${ }^{10}$ emphasizes this issue as follows: "This allows the faculty member to monitor the progress and respond to the recommendations given by the chairperson and the dean."

i. Do not accept that ET faculty are different; rather, emphasize how they are the same.

j. Have discussions with other faculty across campus to subtly emphasize the "sameness" of the ET faculty and their colleagues.

k. Make sure that faculty members are involved in campus activities. Remind them that collegiality is important, and that it is essential to be recognized as a positive contributor to the campus mission when tenure time arrives.

1. Be bottom-line oriented when ET faculty balk at suggestions - be frank in telling them that they could be the losers if they insist on doing it their way.

m. Be a leader and lead.

Advice to faculty on scholarship

New faculty members were provided with the following steps in an effort to maximize performance in the all important area of scholarship:

a. Write a development plan immediately upon arriving on campus. The plan should include a year by year summary of projected work, publications by type (pedagogical or technical), funding issues, conferences to attend - basically a five-year plan for faculty.

b. Start with an ASEE paper concerning pedagogy, with a mentor, the first year as a faculty member. This step forces each member to write immediately upon entering the tenure stream: an extremely important step for those coming from industry and those without a Doctorate. Writing for a proceedings, and presenting the results at a conference highlights the importance of scholarship while teaching and service are also emphasized.

c. Prepare a yearly dossier, or build the tenure dossier each year to determine progress. This makes visual inspection of progress an easy chore and keeps the focus on weaker areas.

d. Have a yearly evaluation and counseling session. This provides a feedback mechanism to keep faculty on track. It also serves as a way to update faculty on changes in the tenure process or interpretations of the tenure guidelines.

e. Change focus from pedagogy to technically based scholarship within three years to ensure publication of technical papers before the tenure decision year.

f. Develop an interdisciplinary scholarly relationship if possible. Publications across disciplines are interesting and speak to the collegiality issue.

g. Find people to be reviewers of the tenure packet early on and network with them at any level possible.

h. Assemble the dossier early and ask the questions: Am I ready for tenure? Would I promote myself?

i. Continue to work as the dossier is being reviewed since new material is allowed at some institutions to the very last minute. 
Experienced faculty were provided similar guidelines with an emphasis on mentoring of junior faculty and a focus on pedagogy and the introduction of consulting work into the classroom through the Scholarship of Application. Similar reviews are conducted yearly with those wishing to go on to the rank of Professor. Each faculty member is required to prepare dossiers in the same manner as the tenure-stream faculty. This provides the senior faculty with the same guidelines and perpetuates the development of the faculty as a whole.

\section{Results}

Someone once said that the proof is in the pudding. In this case, the pudding is good. Seven successful contract renewals. One promotion to full professor: a faculty member with a Master's degree and 3 previous tries before the introduction of the process. One successful tenure and promotion case and one ready to go. These faculty members took the steps to heart and worked diligently to achieve at the highest level. Success has been a team effort and each is contributing to the success of the organization at the same time they are personally successful.

\section{Conclusions}

There are rules at every University concerning the attainment of tenure and promotion. Breaking the code is nothing more than reading the rules, understanding them and then ensuring that the faculty work toward satisfying those rules. It is instilling a "sameness" of ET faculty with the other faculty of the university. It is about being good citizens of the university rather than being complainers and, at times, arrogant participants. It is about leaders who determine the rules and enforce them. It is about faculty willing to do their part to ensure their success and willing to trust the leadership. It is about teams. Mostly, it is about paying attention to successes and failures of others within the university community.

\section{REFERENCES}

1. Samples, J.W., Bearden, K., Harter, D.D., "Finding and Keeping Good Faculty," Proceedings of the 1999

American Society for Engineering Education annual Conference and Exposition, Charlotte, NC.

2. Marino, B.E. and Yost, S.A., "Optimizing Mentor/Mentee Relationships in Academia," Proceedings of the 1998 American Society for Engineering Education annual Conference and Exposition, Seattle, WA.

3. Samples, J.W., "Professional Development for ET Faculty: Using Consulting as Scholarship," Proceedings of the 2004 American Society for Engineering Education annual Conference and Exposition, Salt Lake City, UT.

4. Rose, Andrew T., "Consulting and Industrial Experience as Related to Promotion and Tenure of Engineering Technology Faculty," Proceedings of the 2001 American Society for Engineering Education annual Conference and Exposition, Albuquerque, NM.

5. Sanders, M., "Tenure and Promotion Process: A Case Study Analysis," Journal of Industrial Teacher Education, 25(2) 48-59, 1988.

6. Akinkuoye, N. and Odesina, O., "Factors that Aid in the Promotion and Retention of Engineering Technology Faculty," Proceedings of the 1998 American Society for Engineering Education annual Conference and Exposition, Seattle, WA.

7. Buchanan, W.W., "Expectations for Faculty Development in Engineering Technology," Proceedings of the 1997 American Society for Engineering Education annual Conference and Exposition, Milwaukee, WI.

8. Lahidji, B., "Preparation for Tenure and Promotion - Quality and Quantity," Proceedings of the 1998 American Society for Engineering Education annual Conference and Exposition, Seattle, WA.

Proceedings of the 2005 American Society for Engineering Education Annual Conference and Exposition Copyright C 2005, American Society for Engineering Education 
9. Boyer, Ernest, L., Scholarship Reconsidered, The Carnegie Foundation, Princeton, NJ, 1990.

10. Johnson, K.V., "Tenure and Promotion: The plan, the report, and the evaluation," Proceedings of the 1999 American Society for Engineering Education annual Conference and Exposition, Charlotte, NC.

DR. JERRY SAMPLES holds a BS Ch.E. from Clarkson College, MS and Ph.D. in ME from Oklahoma State University. Dr. Samples served at the United States Military Academy twelve years before assuming the position of Director of the Engineering Technology Division at the University of Pittsburgh at Johnstown in 1996. He is currently the Vice President for Academic and Student Affairs at the University of Pittsburgh at Johnstown. 